
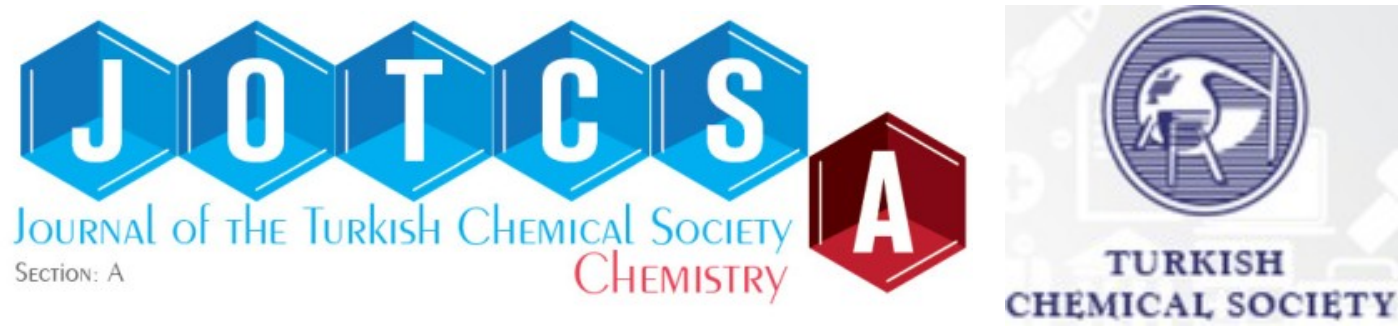

\title{
cis-2 and trans-2-eicosenoic Fatty Acids Inhibit Mycobacterium tuberculosis Virulence Factor Protein Tyrosine Phosphatase B
}

\author{
Lalu Rudyat Telly Savalas ${ }^{*} \Delta$ D , Asih Chomsa Lestari² $\triangle$ iD, Munirah Munirah ${ }^{3}$ iD,

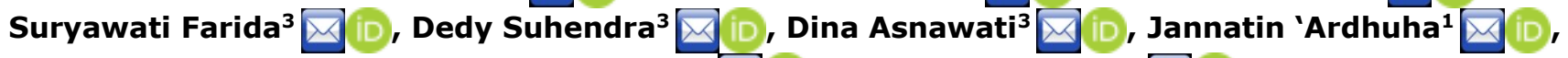 \\ Baiq Nila Sari Ningsih ${ }^{1,4}, D$, and Jufrizal Syahri ${ }^{5}$ iD
}

\begin{abstract}
${ }^{1}$ Department of Mathematics and Natural Sciences, Faculty of Teacher Training and Education, University of Mataram, Jl. Majapahit No. 62 Mataram, Nusa Tenggara Barat, Indonesia 83125.

${ }^{2}$ National Agency of Drugs and Food Control, Jl. Catur Warga Mataram, Nusa Tenggara Barat, Indonesia 83121.

${ }^{3}$ Department of Chemistry, Faculty of Mathematics and Natural Sciences, University of Mataram, Jl. Majapahit No. 62 Mataram, Nusa Tenggara Barat, Indonesia 83125.

${ }^{4}$ Division of Physical Science, Faculty of Science, Prince Songkla University, Hat Yai, Songkla 90110, Thailand.

${ }^{5}$ Department of Chemistry, Universitas Muhammadiyah Riau, Jl. KH. Ahmad Dahlan No.88, Pekanbaru, Riau 28156, Indonesia.
\end{abstract}

\begin{abstract}
The present study aims to investigate the potential inhibitory effect of eicosenoic fatty acids on protein tyrosine phosphatase B of Mycobacterium tuberculosis (PtpB). PtpB is recognized to play a vital role in Mycobacterium tuberculosis (Mtb) successful latent infection. It prevents the fusion even between phagocytosed mycobacteria with lysosomes so that the bacteria escape from degradation. We have overexpressed recombinant Mtb PtpB within Escherichia coli BL21(DE3), and further, we have used the protein for inhibition assay with cis-2 and trans-eicosenoic fatty acids. It is revealed that at a concentration of 16 $\mu \mathrm{M}$, cis-2- and trans-2-eicosenoic fatty acids can inhibit PtpB by $63.72 \%$ and $74.67 \%$, respectively. Docking analysis has confirmed strong interactions of PtpB with cis-2 and trans-2-eicosenoic fatty acids, with the binding energy of -60.40 and $-61.60 \mathrm{kcal} / \mathrm{mol}$, respectively. These findings underline both fatty acids' high potential to be further investigated to discover drugs against latent tuberculosis infection.
\end{abstract}

Keywords: Eicosenoic fatty acid, latent tuberculosis infection, protein tyrosine phosphatase B, molecular docking.

Submitted: March 26, 2021. Accepted: July 26, 2021.

Cite this: Savalas L, Lestari A, Munirah M, Farida S, Suhendra D, Asnawati D, et al. cis-2 and trans-2eicosenoic Fatty Acids Inhibit Mycobacterium tuberculosis Virulence Factor Protein Tyrosine Phosphatase B. JOTCSA. $2021 ; 8(3): 873-82$.

DOI: https://doi.org/10.18596/jotcsa.896489.

*Corresponding author. E-mail: telly@unram.ac.id. Phone +62 (0370) 623873, Fax +62 (0370) 634918

\section{INTRODUCTION}

The World Health Organization estimates that Mtb infects one-fourth of the world population in a latent fashion $(1,2)$. Although not all infections develop into active tuberculosis cases, the number of people with tuberculosis (TB) is still very high. There are 10 million new TB cases with a death rate of 1.2 million registered annually (1).
At the onset of $M$. tuberculosis infection, macrophages -the host cells that act as the first line of the defense system- engulf the bacteria in a process called phagocytosis. Phagocytosis results in membrane-enclosed structures called phagosomes. Phagosomes undergo a series of maturation processes by fusion with early endosomes, late endosomes, and lysosomes. This maturation process includes several stages to form early, 
intermediate, and, finally, mature phagolysosomes (3). The presence of specific marker proteins characterizes each stage. The mature form of phagolysosome is a membrane-enclosed structure with an acidic lumen ( $\mathrm{pH} 4.5)$ containing an array of lysosome-derived proteases/hydrolases and reactive oxygen species (ROS). They collectively serve as host weapons to degrade invading bacterial cells (4).

Together with monocytes and dendritic cells, macrophages constitute the mononuclear phagocyte system (MPS). The hallmark of this system is the recognition and elimination of pathogens (5). Mtb and related species, however, are equipped with the ability to evade the hostile environment of macrophage cells. Mtb does this by secreting different types of molecules that can interfere and prevent phagosome fusion with lysosomes, which are otherwise lethal for the Mtb bacteria. They include mycobacterial lipid and glycolipid such as trehalose-6,6'-dimycolate (TDM) and lipoarabinomannan (LAM), respectively. TDM has been shown to facilitate Mtb survival by decreasing phagosomal acidification and phagolysosomal fusion in murine macrophage (6). LAM was reported to inhibit early phagosomal markers (7). The mycobacterial may also secrete proteins or enzymes, such as protein tyrosine phosphatase $A$ (PtpA), protein tyrosine phosphatase B (PtpB), secretory acid phosphatase $M$, zinc-dependent metalloprotease 1 , lipoamide dehydrogenase $C$, serine/threonine protein kinase G (PknG), and PEPGRS62 protein $(5,8)$. These proteins have been demonstrated to play important roles in the Mtb survival from macrophage elimination. Once the bacteria escaped from the degradation process, they enter a latent infection phase (9). This so-called latent tuberculosis infection (LTBI) can last for years and even decades before resurrecting into active TB (10). Therefore, understanding the interactions between the Mtb pathogen and host macrophages is essential to overcome tuberculosis.

PtpA and PtpB are among the proteins secreted by $\mathrm{Mtb}$, and both of them play a role in facilitating the persistence of mycobacterial infection (11). Deletion of PtpA and PtpB reduces Mtb survival within macrophages and dramatically reduces the Mtb bacillary load in the lung of chronical guinea pigs $(12,13)$. Researchers proposed PtpA to interfere with the formation of the acidic lysosome by blocking the $\mathrm{V}$-type proton pump responsible for the lysosome's acidification $(14,15)$. The void of acidification eventually switches the lysosomal hydrolases into an inactive form, a condition that favors Mtb's survival (16). Likewise, PtpB protein phosphatase is also known to promote mycobacterial survival from host degradation. A recent report suggested that $\mathrm{PtpB}$ reduces the expression of proinflammatory cytokines as well as the apoptosis of macrophages (17). It also limits macrophages' bactericidal responses by inhibiting NF- $\kappa B$ and MAPK signaling pathways (18). Therefore, these phosphatases constitute a high potential to be research targets due to their essential role in Mtb infection.

It has recently been shown that cis-2 and trans-2eicosenoic fatty acids can inhibit PtpA (19). A few reports suggest that PtpA and PtpB have common inhibitors, although the inhibitory effect may vary (20). In this context, the present study aims to reveal whether cis-2 and trans-2-eicosenoic fatty acids can also inhibit PtpB.

\section{MATERIALS AND METHODS}

\section{Materials}

Recombinant plasmid pET-30a bearing $M$. Tuberculosis PtpB is maintained in Escherichia coli strain XL1-Blue. The strain BL21(DE3) of E. Coli was used for expression. Bacterial growth media was standard lysogeny broth (LB), which consisted of $0.5 \%$ yeast extract (BD), 1\% Tryptone (Bio Basic), $1 \% \mathrm{NaCl}$ (Merck), $2 \%$ bacto agar (Difco) for plated culture, and $25 \mu \mathrm{g} / \mathrm{mL}$ kanamycin (Bioworld). The inducer of gene expression was Isopropyl 1-thio- $\beta$ D-galactopyranoside (IPTG), supplied by Thermo Scientific, whereas the substrate for PtpB was paranitrophenyl phosphate ( $p N P P$, Sigma). Materials for SDS PAGE were acrylamide and bis-acrylamide (Bio Basic), sodium dodecyl sulfate (Bio Basic), tetramethylethylenediamine (Bio Basic), ammonium persulfate (Bio Basic), glycine (Bio Basic), betamercaptoethanol (Sigma), bromophenol blue, and Coomassie Brilliant Blue (Sigma), dithiothreitol (Sigma) and protein ladder (Thermo Scientific). Sample degradation by protease was prevented by the addition of Phenylmethylsulfonyl fluoride (PMSF, Sigma). Guanidine hydrochloride $(\mathrm{GuHCl})$ was purchased from MP BioScience.

Inhibitor cis-2- and trans-2-eicosenoic fatty acids were purchased from Larodan AB. Trans-11eicosenoic acid and sodium orthovanadate were purchased from Sigma. S-((3S,10R,13R)-10,13dimethyl-17-octyl-2,3,4,7,8,9,10,11,12,13,14,15, 16,17-tetradecahydro- 1H-cyclopenta[a] phenanthren-3-yl) nonanethioate or DTP was purchased from Interbioscreen. The inhibitors structures are shown in Table 1.

DMSO (MP BioScience) was used as the solvent for the substrate in the presence of imidazole (Thermo Scientific). Graphics were plotted in Graphpad Prism 7. Docking analysis was performed by Discovery Studio (Accelrys, San Diego, CA, USA). 
Table 1: Compounds tested their inhibitory effect on PtpB.

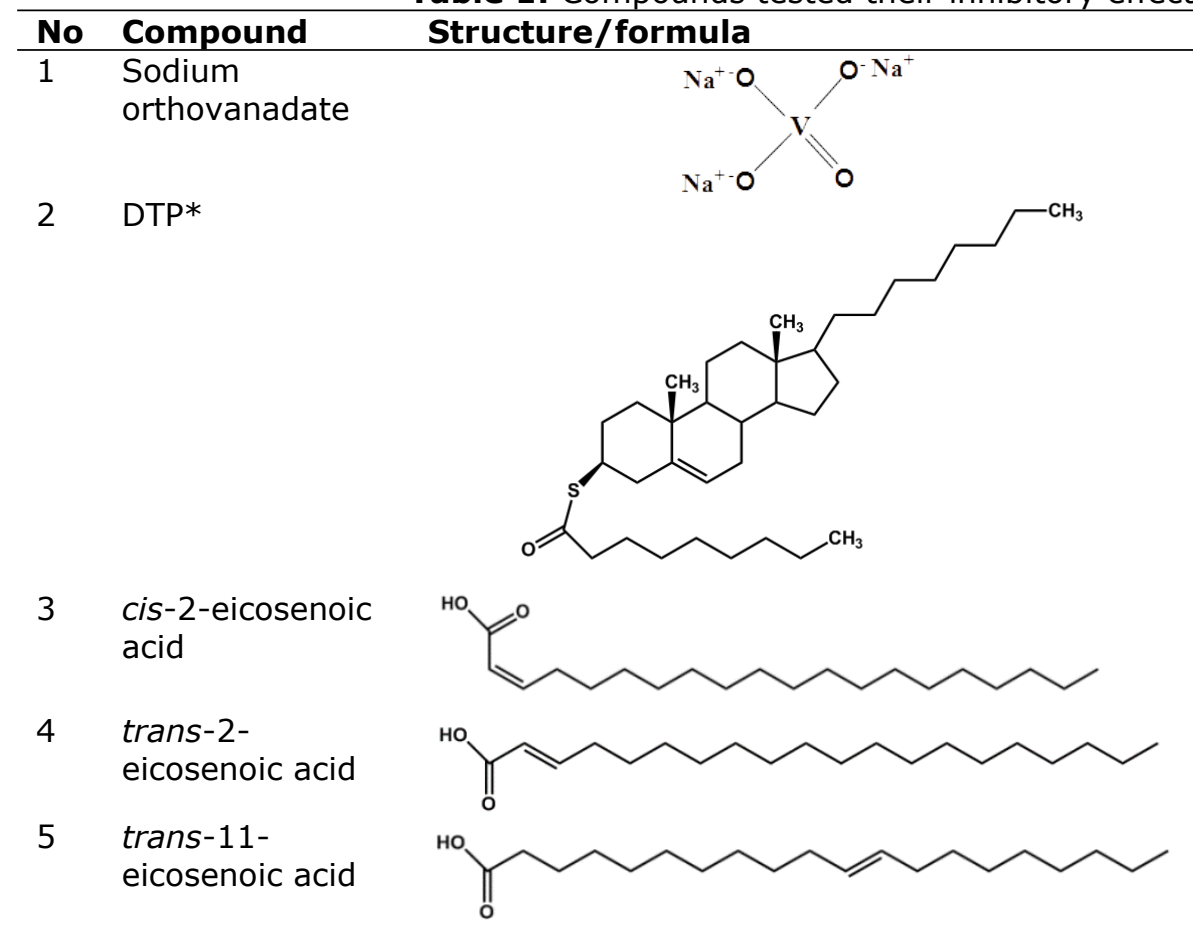

Note
general inhibitor for
phosphatases as a
control (21)

proposed to inhibit PtpB

PtpA inhibitor (19)

PtpA inhibitor (19)

a related fatty acid with double bond position lies apart from carboxyl group

*) DTP: S-((3S,10R,13R)-10,13-dimethyl-17-octyl-2,3,4,7,8,9,10,11,12,13,14,15,16,17-tetradecahydro$1 \mathrm{H}$-cyclopenta[a]phenanthren-3-yl) nonanethioate

\section{Methods}

Expression and Production of PtpB

The recombinant $\mathrm{pET} 30 \mathrm{a}$ plasmid bearing the Mtb $P t p B$ gene was used to transform Escherichia coli $B L 21(D E 3)$. Expression of PtpB under the control of T7 promotor within the pET30a vector was induced by adding $0.5 \mathrm{mM}$ IPTG to the culture of transformant $E$. coli (23) in its early log phase, i.e., when the culture reached to $\mathrm{OD}_{600}$ of "0.3. Incubation of $E$. coli culture was prolonged at $37^{\circ} \mathrm{C}$ with a shaking speed of $250 \mathrm{rpm}$ and harvested after 4 hours of induction. The high PtpB expression leads to the formation of an inclusion body (IB), which is further subjected to the recovery process described below.

\section{Recovery of PtpB and activity assay}

Recovery of PtpB from inactive IB was made resolubilization and dialysis against refolding buffer, as described elsewhere (24). Briefly, IB was washed three times with wash buffer $(50 \mathrm{mM}$ Tris $\mathrm{pH} 8 ; 0.1$ $\mathrm{mM} \mathrm{NaCl} ; 0.1 \mathrm{mM}$ EDTA, 5\% glycerol; $0.1 \mathrm{mM}$ DTT, and $5 \%$ Triton $X-100)$. In each washing step, IB suspension was sonicated and recovered by centrifugation at $14.000 \mathrm{rpm}$ at $4^{\circ} \mathrm{C}$ for 10 minutes. No Triton X-100 was added in the second and third washing steps. The washed IB was further dissolved in the same buffer containing $6 \mathrm{M} \mathrm{GuHCl}$ and shaken vigorously $(250 \mathrm{rpm})$ until a clear lysate was observed. The denatured protein was transferred into a dialysis tube (Carolina Biological Supply Company) with a cutoff between 12,000 to 14,000 Daltons. The dialysis was undertaken against refolding buffer (20 mM Tris $\mathrm{pH} 8 ; 5 \mathrm{mM}$ EDTA; 5 $\mathrm{mM} \mathrm{DTT} ; 50 \mathrm{mM} \mathrm{NaCl}, 20 \%$ glycerol, and $0.32 \mathrm{M}$ $\mathrm{GuHCl}$ ) overnight. On the next day, the refolding buffer was exchanged, and dialysis further proceeded for two hours. The buffer exchange and dialysis cycle were subsequently repeated for two times.

A time-course curve that shows the activity of recombinant $\mathrm{PtpB}$ was created by plotting the absorbance of para-nitrophenol over time. pNP is the product of para-nitrophenyl phosphate hydrolysis by PtpB. The reaction was carried out in a 96 well-plate containing $40 \mu \mathrm{L}$ of $100 \mathrm{mM}$ imidazole, $20 \mu \mathrm{L}$ of $50 \mathrm{mM}$ pNPP substrate, $135 \mu \mathrm{L}$ mili-Q water, and $5 \mu \mathrm{L}$ of recovered PtpB in a total volume of $200 \mu \mathrm{L}$. The reaction was allowed to proceed within the spectrophotometer chamber (Multiskan Go, Thermo Scientific). The spectrophotometer was set to automatically record the absorbance at 410 $\mathrm{nm}$ in five minutes intervals for two hours.

Inhibition of PtpB with cis-2 and trans-2-eicosenoic fatty acids

We have performed an inhibition assay of PtpB with a procedure adapted from Mascarello et al. (20). The reaction mixture contained 100 ng PtpB (in phosphate buffer, $\mathrm{pH} 8.0$ ), $20 \mathrm{mM}$ imidazole, $20 \mathrm{mM}$ pNPP substrate, $16 \mu \mathrm{M}$ inhibitor (Table 1), and Milli$\mathrm{Q}$ water to complete the reaction volume to $200 \mu \mathrm{L}$ in a 96-well plate. The reaction was carried out at $37^{\circ} \mathrm{C}$. After 15 minutes, the reaction was stopped 
by the addition of $80 \mu \mathrm{L}$ of $0.25 \mathrm{M} \mathrm{NaOH}$, and the absorbance was recorded at $410 \mathrm{~nm}$ immediately. PtpB activity was calculated by the following equation:

$$
A=\frac{\text { Vol } \times \Delta A 410}{\epsilon \times \text { time }}
$$

Where

A : activity (Unit)

Vol : reaction mixture volume $(\mu \mathrm{L})$

$\Delta \mathrm{A}_{410}$ : sample absorption - blank absorption, measured at $410 \mathrm{~nm}$

$\varepsilon \quad:$ molar extinction of pNP $\left(1.78 \times 10^{4} \mathrm{M}^{-}\right.$ $\left.{ }^{1} . \mathrm{cm}^{-1}\right)$

$\mathrm{t} \quad$ : measurement time (minutes)

Molecular Docking

In order to describe the interaction between PtpB with the inhibitor molecules, we have performed docking analysis by using the software Discovery Studio (Biovia, Accelrys, San Diego USA). The protein structure of PtpB was retrieved from RCSB Protein Data Bank with accession number 1YWF.

\section{RESULTS AND DISCUSSION}

The required material for the inhibition assay was prepared by over-expressing the Mtb PtpB gene in E. Coli BL21(DE3). We found that the protein exists as an IB (Figure 1A). Despite initially being inactive protein, expression as IB offered a high protein level that can be recovered by an established procedure to gain protein with sufficient purity for inhibition assays. As shown in Figure $1 \mathrm{~B}$, re-solubilization with $6 \mathrm{M} \mathrm{GuHCl}$ followed by dialysis effectively removes the excessive salt. The application of $\mathrm{GuHCl}$ gave a better result compared to previous work with $8 \mathrm{M}$ urea (24). The observation might come from the relatively efficient solubilization of the IB by $\mathrm{GuHCl}$ compared to urea (25).

The re-solubilized protein was active, as shown by its ability to cleave pNPP substrate into paranitrophenol and phosphate.

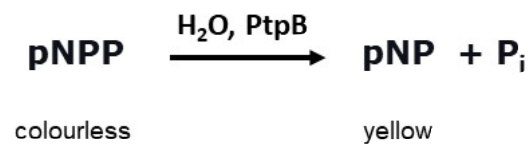

The absorbance of the reaction mixture was recorded at $410 \mathrm{~nm}$ every five minutes for two hours. The data was plotted in a time-course curve (Figure 1C). The curve showed good linearity within the first 45 minutes. We employed this reaction to test whether prospective inhibitors (Table 1) can decrease PtpB activity. The inhibition mixture containing PtpB, substrate pNPP, and inhibitor was allowed to react, and the absorbance at $410 \mathrm{~nm}$ was recorded after 15 minutes of reaction.

\section{A. PtpB expression in} E. coli BL21(DE3)

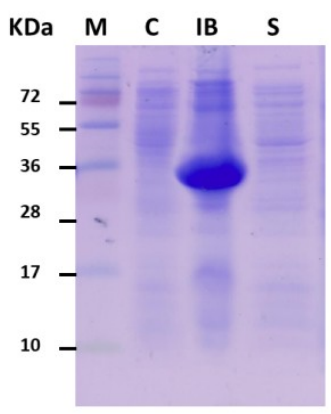

B. Resolubilization of PtpB

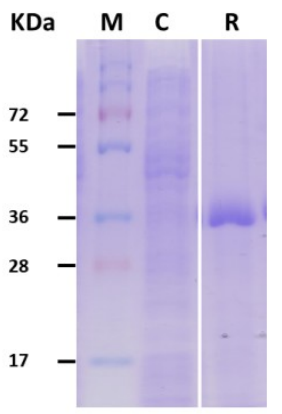

Figure 1: Expression of PtpB in E. coli BL21(DE3).
A. Expression of PtpB in E. coli BL21(DE3) under IPTG induction. $M$ : protein ladder; $C$ : untransformed $E$. coli extract; IB: inclusion body found in the insoluble fraction; $\mathrm{S}$ : soluble fraction or supernatant.

B. Solubilization of PtpB with Guanidine hydrochloride and its recovery in refolding buffer. $M$ : protein ladder; C: lysate from untransformed $E$. coli; R: recovered PtpB. Proteins were separated by $12.5 \%$ SDS-PAGE.

C. Activity of recombinant PtpB was measured over time. PtpB hydrolyzed pNPP substrate to release the yellow color of para-nitrophenol. The absorbance was measured at $410 \mathrm{~nm}$ at 5-minute intervals for 120 minutes.

We tested the inhibitory effect of cis-2 and trans-2 eicosenoic fatty acids on the activity of PtpB. In this preliminary work, we employed a single dose of inhibitors of $16 \mu \mathrm{M}$ that represent a low dose (26). Figure 2 shows the activity of PtpB is reduced by cis-2 and trans-2-eicosenoic fatty acids to $36.28 \%$ and 25.33, respectively. In other words, cis-2 and trans-2-eicosenoic fatty acids inhibit PtpB by 
$63.72 \%$ and $74.67 \%$, respectively. The inhibition of PtpB by trans-2-eicosenoic fatty acid was in line with the effect of sodium orthovanadate, a general inhibitor for phosphatases (27). In an in silico study, Dhanjal and co-workers suggested that the compound DTP is a potential inhibitor for PtpB (22). We also showed for the first time that DTP inhibits PtpB with a slightly less effect than cis-2 and trans2-eicosenoic acids. Trans-11-eicosenoic fatty acid, a related fatty acid whose double bond lies apart from the carboxyl group, only slightly inhibited PtpB activity (Figure 2). It showed that the double bond position that is close to the carboxy group is crucial for cis-2- and trans-2-eicosenoic to inhibit PtpB.

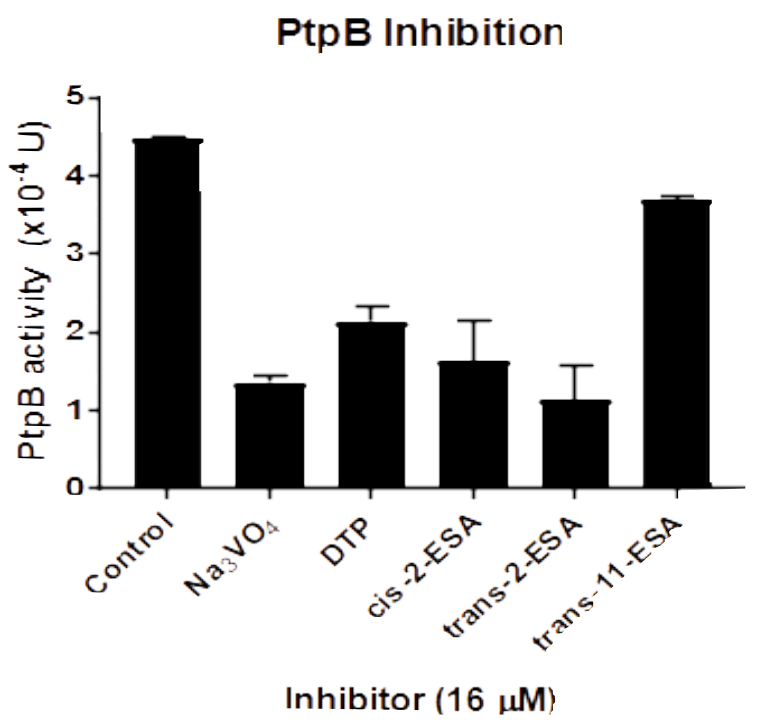

Figure 2: The activity of PtpB in the presence of several inhibitors.
PtpB activity in the presence of several inhibitors at a concentration of $16 \mu \mathrm{M}$. Control: PtpB without inhibitor. Inhibition by sodium orthovanadate $\left(\mathrm{Na}_{3} \mathrm{VO}_{4}\right)$, DTP, cis-2-eicosenoic fatty acid, trans-2fatty acid, and trans-11-fatty acid correspond to $69.44 \%, 52.22 \%, 63.72 \%, 74.67 \%$ and $17.53 \%$, respectively, with regard to control. All data are averages of two measurements. ESA: eicosenoic fatty acid.

To reveal the interaction between those inhibitors with PtpB, we performed a docking experiment. Figure $3 \mathrm{~A}-\mathrm{B}$ shows that both cis-2 and trans-2eicosenoic acids fit the active site of the PtpB structure with the binding energy of -60.40 and $61.60 \mathrm{kcal} / \mathrm{mol}$, consecutively. These values are closed to the cDocker energy of native phosphate ligand of $-81.47 \mathrm{kcal} / \mathrm{mol}$; Table 2). This shows that both cis-2 and trans-2-eicosenoic fatty acids have stable interaction with PtpB. The strong interactions are supported by the presence of three and four hydrogen bonds between cis-2 and trans-2eicosenoic fatty acids, respectively, with critical amino acids of PtpB. Besides, both hydrophobic inhibitors are assumed to have a pi stacking $(\pi-\pi$ stacking) interaction with the aromatic ring of Phe 98 residue. A weaker interaction of PtpB is observed with trans-11-eicosenoic fatty acid. Although trans11-eicosenoic fatty acid forms three hydrogen bonds and an attractive charge interaction with PtpB, the lack of pi stacking interaction seems to be responsible for the weaker interaction (summarized in Table 2). Based on the binding energy and the presence of hydrogen bonds between cis- 2 and trans-2-eicosenoic fatty acids with PtpB, it can be concluded that both fatty acids have high inhibition activity against the virulence factor of Mtb. This finding is also in agreement with the in vitro inhibition assay described in Figure 2. 


\section{A. Complex of PtpB and cis-2-eicosenoic acid}

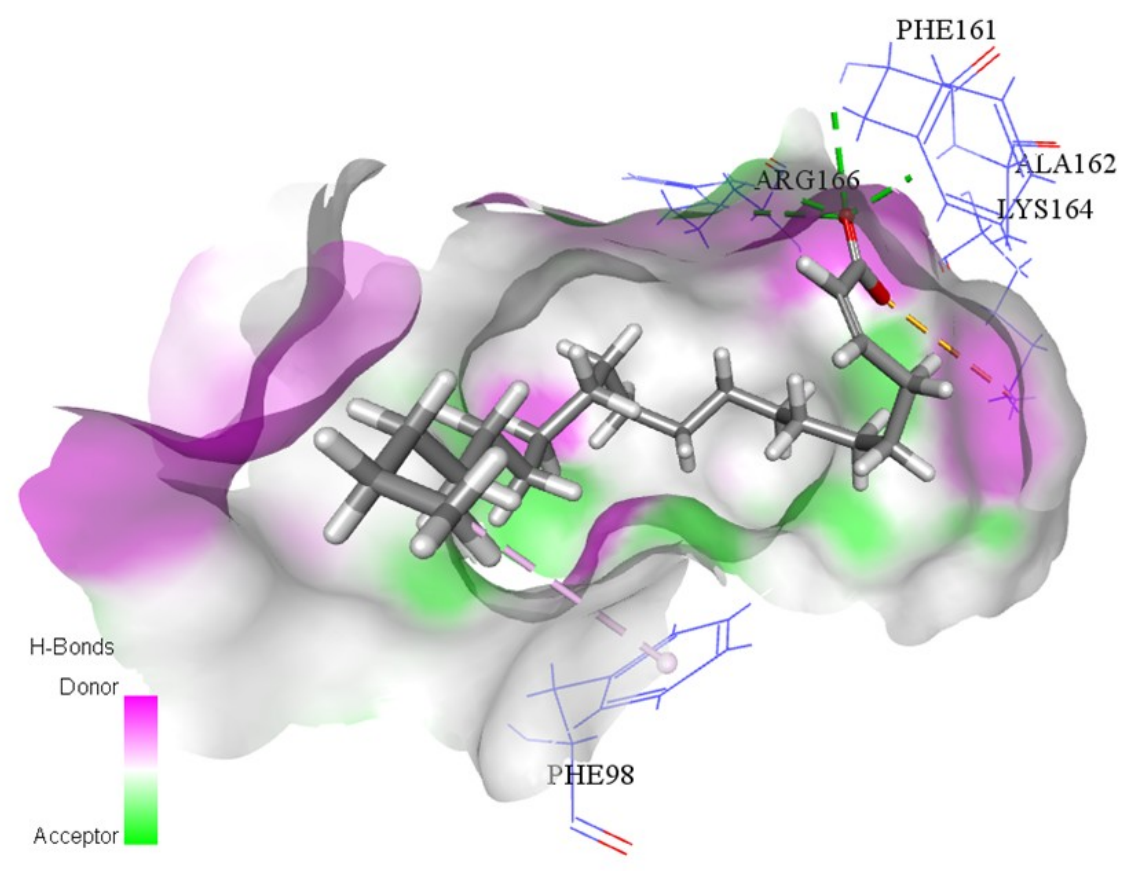

C. Complex of PtpB and trans-11-eicosenoic acid

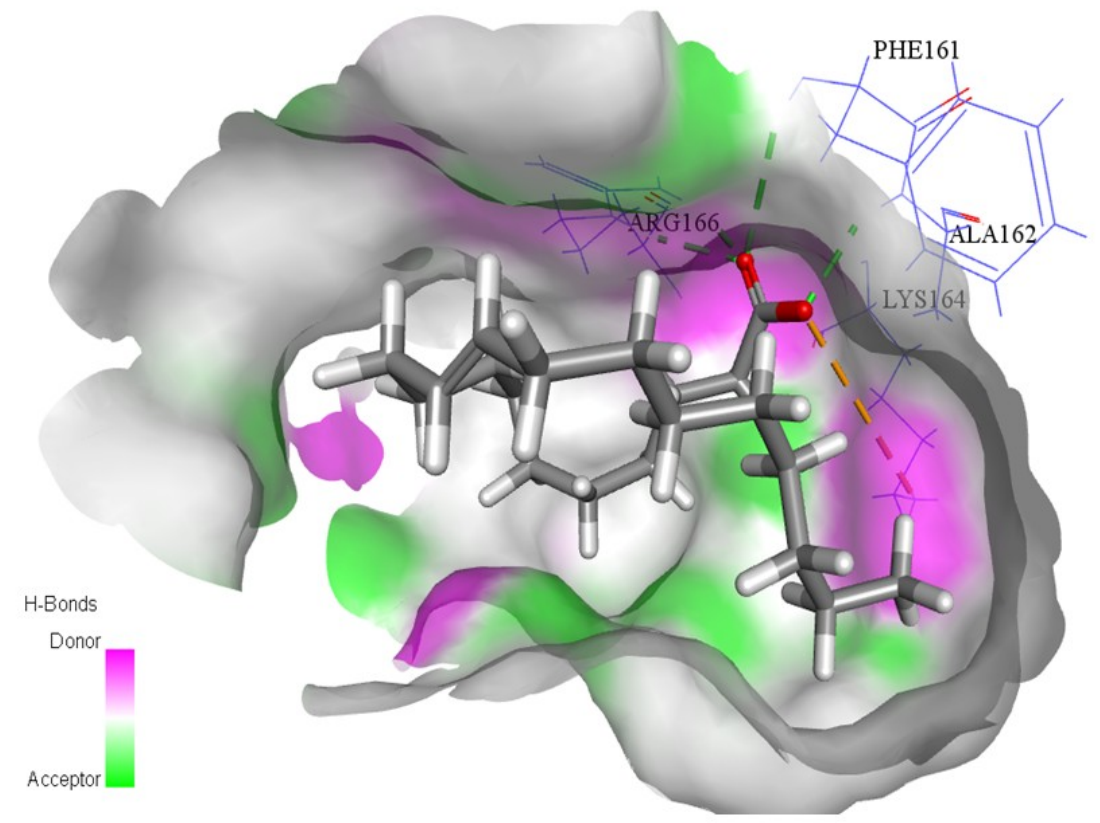




\section{B. Complex of PtpB and trans-2-eicosenoic acid}

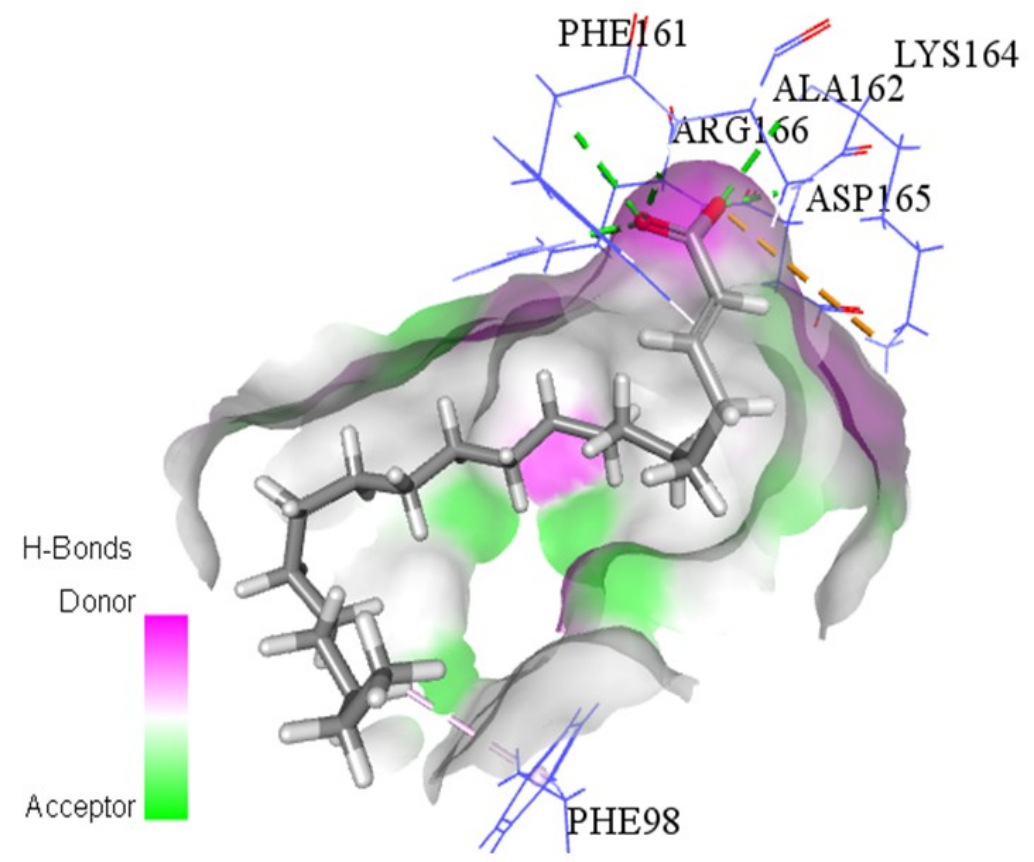

Figure 3: Docking of PtpB with selected inhibitors.

The strong interaction of PtpB with cis-2 and trans-2 eicosenoic fatty acids is supported by three potential hydrogen bonds of the protein through residues Phe 161, Ala $_{162}$, and Arg 166 . The interaction is also strengthened by the presence of attractive charge interaction with the positively charged residue Lys 164 , which is also observed with trans-11-eicosenoic fatty acid ( $A-C)$. An additional hydrogen bond between PtpB with trans-2-eicosenoic acid via $A_{s p_{165}}$ (B) confirmed the more potent inhibitory effect of trans-2-eicosenoic acid than its cis-2 isomer (A). In contrast to the cis-2 and trans-2-eicosenoic fatty acids, a Pi stacking ( $\Pi$ - $\Pi$ stacking) interaction is absent in the docking of PtpB with trans-11-eicosenoic fatty acid (C).

Table 2: Docking parameters of PtpB with several inhibitors.

\begin{tabular}{|c|c|c|}
\hline Compound & $\begin{array}{l}\text { cDocker } \\
\text { (kcal/mol) }\end{array}$ & Interaction \\
\hline cis-2-eicosenoic acid & $-60,3957$ & $\begin{array}{l}\text { Hydrogen bonds: } \text { Phe }_{161}, \text { Arg }_{166}, \text { Ala }_{162} \\
\text { Pi stacking ( } \Pi-\Pi \text { stacking): Phe } \\
\text { Attractive Charge: Lys } 164\end{array}$ \\
\hline $\begin{array}{l}\text { trans-2-eicosenoic } \\
\text { acid }\end{array}$ & $-61,6195$ & $\begin{array}{l}\text { Hydrogen bonds: } \text { Phe }_{161}, \text { Arg }_{166}, \text { Ala }_{162}, \text { Asp }_{165} \\
\text { Pi stacking ( } \Pi-\pi \text { stacking): Phe } 98 \\
\text { Attractive Charge: Lys } 164\end{array}$ \\
\hline $\begin{array}{l}\text { trans-11-eicosenoic } \\
\text { acid }\end{array}$ & $-55,4227$ & $\begin{array}{l}\text { Hydrogen bonds: Phe } 161, \text { Arg }_{166}, \text { Ala }_{162} \\
\text { Attractive Charge: Lys } 164\end{array}$ \\
\hline $\begin{array}{l}\text { co-crystalized ligand } \\
\mathrm{PO}_{4}{ }^{2-}\end{array}$ & $-81,4651$ & $\begin{array}{l}\text { Hydrogen bonds: Phe } 161, \text { Ala }_{162}, \text { Lys }_{164}, \text { Asp }_{165}, \text { His94, } \\
\text { Pro } 81 \\
\text { Pi stacking ( } \Pi-\Pi \text { stacking): Phe } 98, \text { Tyr }_{125}, \text { Leu }_{227} \text {, } \\
\text { Leu }_{101}, \text { Val }_{231} \\
\text { Attractive Charge: } \text { Met }_{126}\end{array}$ \\
\hline
\end{tabular}

Although the primary host substrate of PtpB is primarily unknown, accumulated evidence emphasizes the crucial role of PtpB in preventing the host degradative pathway (28). Hence, targeting $\mathrm{PtpB}$ to prevent the onset of latent tuberculosis infection has lead to the screening of many potential inhibitors (29). Various types of compounds, either naturally occurring or modified compounds, have been reported to inhibit PtpB. A series of chalcones derivatives, for example, has 
been reported to inhibit PtpB at low micromolar concentration, i.e., with $\mathrm{IC}_{50}<30 \mu \mathrm{M}$ (27). Further development has expanded the inhibition at submicromolar concentration, such as reported by Liu and coworkers who tested polypropionate derivatives isolated from deep-see fungus to inhibit PtpB. They revealed that the compounds have $\mathrm{IC}_{50}$ in the range of 5.1 to $12 \mu \mathrm{M}$ (30). Here we demonstrated that cis-2 and trans-2-eicosenoic fatty acids strongly inhibit PtpB. This finding could be helpful for the development of drugs to prevent latent tuberculosis infection. Targeting PtpB offers an advantage since the protein is secreted into the macrophage's cytoplasm. There is no requirement that the inhibitor has to overcome the thick hydrophobic envelope of mycobacteria (14). Moreover, it is also worth considering alternative application strategies; for instance, using the potential inhibitors in combination with first-line TB drugs such as rifampicin and isoniazid as PtpB inhibitors were reported to enhance mycobacterial elimination $(11,31)$. However, before further exploration, the selectivity of inhibition among human phosphatases might also be deemed necessary.

\section{CONCLUSION}

The present study shows that both cis-2 and trans2-eicosenoic fatty are able to inhibit Mtb PtpB. This is also the first report that long fatty acids can inhibit PtpB. The inhibitory potential was also supported by docking analysis. Further study can be directed to investigate whether these compounds can also inhibit macrophage cells or animal model infection by Mtb.

\section{ACKNOWLEDGMENTS}

LRTS and JA received research funding through INSINAS research funding from the Ministry of Research, Technology, and Higher Education in the fiscal year of 2018. The authors thank Siti Rosidah from Bioscience and Biotechnology Research Center, the University of Mataram, for technical assistance.

\section{CONFLICT OF INTEREST}

All authors declare no conflict of interest.

\section{REFERENCES}

1. WHO. Global Tuberculosis Report [Internet]. World Health Organization; URL: https://www.who.int/teams/global-tuberculosisprogramme/tb-reports.

2. Houben RMGJ, Dodd PJ. The Global Burden of Latent Tuberculosis Infection: A Re-estimation Using Mathematical Modelling. Metcalfe JZ, editor. PLoS Med. 2016 Oct 25;13(10):e1002152. DOI: https://doi.org/10.1371/journal.pmed.1002152.
3. Desjardins M, Huber L, Parton R, Griffiths G. Biogenesis of phagolysosomes proceeds through a sequential series of interactions with the endocytic apparatus. Journal of Cell Biology. 1994 Mar $1 ; 124(5): 677-88$.

https://doi.org/10.1083/jcb.124.5.677.

4. Upadhyay S, Mittal E, Philips JA. Tuberculosis and the art of macrophage manipulation. Pathogens and Disease [Internet]. 2018 Jun 1 [cited 2021 Jul 28];76(4): fty037. URL: https://academic.oup.com/femspd/article/doi/10.10 93/femspd/fty037/4970761.

5. Pahari S, Kaur G, Negi S, Aqdas M, Das DK, Bashir $H$, et al. Reinforcing the Functionality of Mononuclear Phagocyte System to Control Tuberculosis. Front Immunol. 2018 Feb 9;9:193. DOI: https://doi.org/10.3389/fimmu.2018.00193.

6. Kansutton C, Jagannath C, Hunterjr R. Trehalose $6,6^{\prime}$-dimycolate on the surface of Mycobacterium tuberculosis modulates surface marker expression for antigen presentation and costimulation in murine macrophages. Microbes and Infection. 2009 Jan;11(1):40-8.

DOI:

https://doi.org/10.1016/j.micinf.2008.10.006.

7. Queval CJ, Brosch R, Simeone R. The Macrophage: A Disputed Fortress in the Battle against Mycobacterium tuberculosis. Front Microbiol. 2017 Nov 23;8:2284. DOI: https://doi.org/10.3389/fmicb.2017.02284.

8. Rankine-Wilson LI, Shapira T, Sao Emani C, AvGay Y. From infection niche to therapeutic target: the intracellular lifestyle of Mycobacterium tuberculosis. Microbiology [Internet]. 2021 Apr 7 [cited 2021 Jul 28];167(4). URL: https://www.microbiologyresearch.org/content/jour nal/micro/10.1099/mic.0.001041.

9. Stutz MD, Clark MP, Doerflinger M, Pellegrini $M$. Mycobacterium tuberculosis: Rewiring host cell signaling to promote infection. J Leukoc Biol. 2018 Feb;103(2):259-68.

https://doi.org/10.1002/JLB.4MR0717-277R.

10. Salina EG, Mollenkopf HJ, Kaufmann SHE, Kaprelyants AS. M. tuberculosis Gene Expression during Transition to the "Non-Culturable" State. Acta Naturae. 2009 Jul;1(2):73-7. URL: https://www.ncbi.nlm.nih.gov/pubmed/22649605

11. Dutta NK, He R, Pinn ML, He $Y$, Burrows $F$, Zhang Z-Y, et al. Mycobacterial Protein Tyrosine Phosphatases $A$ and $B$ Inhibitors Augment the Bactericidal Activity of the Standard Antituberculosis Regimen. ACS Infect Dis. 2016 Mar $11 ; 2(3): 231-9$.

https://doi.org/10.1021/acsinfecdis.5b00133. 
12. Cowley SC, Babakaiff R, Av-Gay Y. Expression and localization of the Mycobacterium tuberculosis protein tyrosine phosphatase PtpA. Research in Microbiology. 2002 May;153(4):233-41. DOI: https://doi.org/10.1016/S0923-2508(02)01309-8.

13. Singh R, Rao V, Shakila $H$, Gupta $R$, Khera $A$, Dhar $N$, et al. Disruption of mptpB impairs the ability of Mycobacterium tuberculosis to survive in guinea pigs. Molecular Microbiology. 2003 Nov; 50(3): 751-62.

DOI:

https://doi.org/10.1046/j.1365-2958.2003.03712.x.

14. Wong D, Chao JD, Av-Gay Y. Mycobacterium tuberculosis-secreted phosphatases: from pathogenesis to targets for TB drug development. Trends in Microbiology. 2013 Feb;21(2):100-9. DOI: https://doi.org/10.1016/j.tim.2012.09.002.

15. Forrellad MA, Klepp LI, Gioffré A, Sabio y García $J$, Morbidoni HR, Santangelo $M$ de la $P$, et al. Virulence factors of the Mycobacterium tuberculosis complex. Virulence. 2013 Jan;4(1):3-66. DOI: https://doi.org/10.4161/viru.22329.

16. Wong D, Bach $H$, Sun J, Hmama Z, Av-Gay $Y$. Mycobacterium tuberculosis protein tyrosine phosphatase (PtpA) excludes host vacuolar-H+ATPase to inhibit phagosome acidification. Proceedings of the National Academy of Sciences. 2011 Nov 29;108(48):19371-6. DOI: https://doi.org/10.1073/pnas.1109201108.

17. Zhou B, He Y, Zhang X, Xu J, Luo $Y$, Wang $Y$, et al. Targeting mycobacterium protein tyrosine phosphatase B for antituberculosis agents. Proceedings of the National Academy of Sciences. 2010 Mar 9;107(10):4573-8. DOI: https://doi.org/10.1073/pnas.0909133107.

18. Fan L, Wu X, Jin C, Li F, Xiong S, Dong Y. MptpB Promotes Mycobacteria Survival by Inhibiting the Expression of Inflammatory Mediators and Cell Apoptosis in Macrophages. Front Cell Infect Microbiol. 2018 May 25;8:171. DOI: https://doi.org/10.3389/fcimb.2018.00171.

19. Savalas LRT, Furqon BRN, Asnawati D, 'Ardhuha J, Sedijani P, Hadisaputra S, et al. Cis-2 and trans2-eisocenoic fatty acids are novel inhibitors for Mycobacterium tuberculosis Protein tyrosine phosphatase A. Acta Biochim Pol [Internet]. 2020 Jun 18 [cited 2021 Jul 28]; DOI: https://doi.org/10.18388/abp.2020 5201.

20. Mascarello A, Mori M, Chiaradia-Delatorre LD, Menegatti ACO, Monache FD, Ferrari F, et al. Discovery of Mycobacterium tuberculosis Protein Tyrosine Phosphatase B (PtpB) Inhibitors from Natural Products. Maga G, editor. PLoS ONE. 2013 Oct $14 ; 8(10)$ :e77081.

https://doi.org/10.1371/journal.pone.0077081.
21. Huyer G, Liu S, Kelly J, Moffat J, Payette P, Kennedy $B$, et al. Mechanism of Inhibition of Protein-tyrosine Phosphatases by Vanadate and Pervanadate. Journal of Biological Chemistry. 1997 Jan;272(2):843-51.

https://doi.org/10.1074/jbc.272.2.843.

22. Dhanjal JK, Grover S, Sharma S, Singh A, Grover A. Structural insights into mode of actions of novel natural Mycobacterium protein tyrosine phosphatase B inhibitors. BMC Genomics. 2014;15(Suppl 1):S3. DOI: https://doi.org/10.1186/1471-2164-15-S1-S3.

23. Laemmli UK. Cleavage of Structural Proteins during the Assembly of the Head of Bacteriophage T4. Nature. 1970 Aug;227(5259):680-5. DOI: https://doi.org/10.1038/227680a0.

24. Savalas LRT, Sedijani $P$, Hadisaputra $S$, Ardhuha J, Lestari CA, Wahidah EN. Expression of Mycobacterium tuberculosis Protein Tyrosine Phosphatase B in Escherichia coli and Its Recovery from Inclusion Body. J Bio Bio Edu. 2017 Dec $31 ; 9(3): 530$.

DOI: https://doi.org/10.15294/biosaintifika.v9i3.12384.

25. Pace CN, Grimsley GR, Scholtz JM, Shaw KL. Protein Stability. In: John Wiley \& Sons Ltd, editor. Protein Science Encyclopedia [Internet]. Chichester, UK: John Wiley \& Sons, Ltd; 2014 [cited 2021 Jul 28]. p. a0003002.pub3. URL: https://onlinelibrary.wiley.com/doi/10.1002/978047 0015902.a0003002.pub3.

26. Mascarello A, Chiaradia LD, Vernal J, Villarino A, Guido RVC, Perizzolo $P$, et al. Inhibition of Mycobacterium tuberculosis tyrosine phosphatase PtpA by synthetic chalcones: Kinetics, molecular modeling, toxicity and effect on growth. Bioorganic \& Medicinal Chemistry. 2010 Jun 1;18(11):3783-9. DOI: https://doi.org/10.1016/j.bmc.2010.04.051.

27. Chiaradia LD, Martins PGA, Cordeiro MNS, Guido RVC, Ecco G, Andricopulo AD, et al. Synthesis, Biological Evaluation, And Molecular Modeling of Chalcone Derivatives As Potent Inhibitors of Mycobacterium tuberculosis Protein Tyrosine Phosphatases (PtpA and PtpB). J Med Chem. 2012 Jan 12;55(1):390-402. DOI: https://doi.org/10.1021/jm2012062.

28. Chai Q, Wang L, Liu $\mathrm{CH}$, Ge B. New insights into the evasion of host innate immunity by Mycobacterium tuberculosis. Cell Mol Immunol. 2020 Sep;17(9):901-13. DOI: https://doi.org/10.1038/s41423-020-0502-z.

29. Mascarello A, Mori M, Chiaradia-Delatorre LD, Menegatti ACO, Monache FD, Ferrari F, et al. Discovery of Mycobacterium tuberculosis Protein Tyrosine Phosphatase B (PtpB) Inhibitors from 
Natural Products. Maga G, editor. PLoS ONE. 2013

Oct $14 ; 8(10)$ :e77081.

https://doi.org/10.1371/journal.pone.0077081.

30. Liu Z, Wang Q, Li S, Cui H, Sun Z, Chen D, et al. Polypropionate Derivatives with Mycobacterium tuberculosis Protein Tyrosine Phosphatase B Inhibitory Activities from the Deep-Sea-Derived Fungus Aspergillus fischeri FS452. J Nat Prod. 2019
Dec

27;82(12):3440-9.

DOI: https://doi.org/10.1021/acs.jnatprod.9b00834.

31. Vickers CF, Silva APG, Chakraborty A, Fernandez P, Kurepina N, Saville C, et al. StructureBased Design of MptpB Inhibitors That Reduce Multidrug-Resistant Mycobacterium tuberculosis Survival and Infection Burden in Vivo. J Med Chem. 2018 Sep 27;61(18):8337-52. DOI: https://doi.org/10.1021/acs.jmedchem.8b00832. 